of Agriculture and Fisheries; Mr. J. W. Salter Chalker, chairman of the Diseases of Animals Committee of the National Farmers' Union; Mr. Charles Dukes, general secretary of the National Union of General and Municipal Workers ; Prof. James Gray, professor of zoology in the University of Cambridge and member of the Agricultural Research Council; Mr. C. M. Holmes, vice-president of the Association of Unqualified Practitioners and Animal Castrators; Mr. W. F. Holmes, member of Council of the Kennel Club; Mr. Robert Hobbs, member of Council of the Royal Agricultural Society of England; Mr. W. D. Jackson, past president of the National Farmers' Union and Chamber of Agriculture of Scotland; Sir Louis Kershaw, member of the Loveday Committee on Veterinary Education; Lieut.-Colonel P. J. Simpson, member of Council of the Royal College of Veterinary Surgeons. The Secretary to the Committee is Mr. G. H. Higgs, of the Ministry of Agriculture and Fisheries, to whom communications should be addressed at 99 Gresham Street (First Floor), London, E.C.2.

\section{Biological Standardization}

Brologrcal standardization is the theme of the Bulletin of the Health Organisation (VI, 10, No. 2; 1942-43. Geneva (London: Allen and Unwin, League of Nations Publications Dept. 4s.) ). The issue contains two articles on the biological standardization of heparin and on a provisional international standard for this substance, and other articles on standard preparations for the assay of the three gas-gangrene antitoxins, on the complexity of the tetanus toxin and on the variable interactions of tetanus toxins and antitoxins. The rest of the issue is occupied by seven articles from the Department of Biological Standards of the National Institute for Medical Research, London. The first of these deals with recent changes relating to international standards for certain sex hormones and for pituitary posterior lobe, due to exhaustion of stocks of the original preparations which had served as international standards for these hormones and the consequent need for their replacement by other samples. The other six articles deal with replacements of the substances of the international standards for the ostrus-producing hormone, for male hormones, progesterone and pituitary posterior lobe and with the international preparation of desiccated ox anterior pituitary gland and the international standard of prolactin.

\section{Status of Statisticians}

The report of the Committee of the Royal Statistical Society on thel Status of Statisticians, appointed by the Council on July 22, 1943 as amended and adopted by the Council, has now been issued. The present position in Great Britain is regarded as unsatisfactory in some respects. First, an employer requiring the services of a statistician on his staff has no common standard among the qualifications which he can accept as a certificate of proficiency, and the report, in confirmation of this point, notes that in recent discussions on the Society's report on official statistics, the Treasury representatives indicated how useful it would be to departments, in considering appointments to responsible positions in statistical branches, if approved statistical qualifications were in existence. The position is also unsatisfactory to an employer, because there are no generally recognized definitions or descriptions of the various types of statistician. It is equally unsatisfactory to the employee, because there is no recognized status in his profession and no generally approved method of distinguishing between a genuinely accomplished man and a mere quack, or even a rank impostor. It is also unsatisfactory to an employee not to have any standards by which he can judge the level of his own attainment, or to which he can work. The situation is unsatisfactory for the general public, which is affected more than it realizes by bad statistical work.

The Committee considers, therefore, that there is a strong case for instituting some method of determining the professional status of statisticians. It believes that the universities must continue to be the main source of training in statistics, and it would welcome any extension of the facilities already provided, although it does not think that the universities can provide adequate tests of proficiency in statistics for all who are likely to require them; also, existing examinations are not sufficient to provide all the requisite professional qualifications. Accordingly the Committee proposes a scheme under which power would be sought by way of a Supplemental Charter to enable the Council of the Royal Statistical Society to confer on approved candidates a diploma in statistics and to issue a certificate to those who pass Part 1 of the examinations. This would provide specifically for those who may be termed statistical computers or junior statisticians. Candidates for the certificate or diploma should not be limited to fellows of the Society, and those for the diploma should be required to pass Parts 1 and 2 of the prescribed examinations, a suggested syllabus for which is appended to the report, and also to show that they had had satisfactory experience of statistical work over a period of not less than two years. A candidate for the certificate or diploma should be exempted from the whole or any section or sections of the examinations. if he has passed examinations approved by the Council. While so far as concerns the scientifie aspects of the Society's work, no change is suggested in the present system of election of fellows, in the qualifications required, or in their title, status and privileges, additional by-laws would be required to regulate the award of the certificate and the diploma.

\section{Astronomy in the U.S.S.R.}

PosT-war astronomical research in the Soviet Union is being planned on a great scale. Nine of the nineteen Soviet observatories were in territory that was overrun by the Germans and have been destroyed or seriously damaged. Most important of these was the Pulkovo Observatory, near Leningrad, which was completely destroyed by air and artillery bombardment. Most of the equipment and the valuable library of the Observatory were removed in time to safer places. The Pulkovo staff has continued astronomical research work at Tashkent, Abastumani and Alma-Ata. Prof. Belyavsky, director of the Observatory, states that it has been decided that reconstruction is to commence immediately and that the instrumental equipment will be reinstalled at Pulkovo at the earliest possible moment, to make possible the resumption of work in fundamental astronomy. More powerful equipment is to be constructed in the U.S.S.R. or obtained from abroad. The Engelhardt, Nikolaeff and Tashkent Observatories will also carry on fundamental observations.

The Moscow News has reported the decisions of 